\title{
Experience of a flu-like illness in the time of COVID-19 and a potential role for turmeric in alleviating symptoms: a case study
}

\author{
Kiran Bhadriraju \\ Theiss Research, 7411 Eads Ave, La Jolla, CA - 92037
}

\section{KEY WORDS}

\section{Turmeric}

Influenza

Common cold

Sinus

Congestion

flu-like illness

Respiratory illness

*Corresponding Author:

Kiran Bhadriraju, PhD

Theiss Research

7411 Eads Ave, La Jolla, CA - 92037

E-mail: k.bhadriraju@theissresearch.org

\begin{abstract}
Turmeric has been known in India since the time of the writing of the Charaka Samhita as a remedy for a wide range of illnesses, including respiratory illnesses. Laboratory investigations in cultured cells in the past several decades have shown that turmeric and its constituents influence signaling pathways and transcription factor activity, changes that are not incompatible with it having a beneficial effect. However, there are currently no rigorously designed modern investigations into the clinical efficacy of turmeric for respiratory illnesses. Here, the consumption of turmeric together with warm milk is anecdotally reported to have provided acute relief from severe congestion during a recent flu-like illness. Since the safety of turmeric has already been demonstrated by thousands of years of use, this report attempts to motivate the direct testing of its clinical efficacy for moderating the severity of flu-like respiratory illnesses in robustly designed clinical trials.
\end{abstract}

doi: $10.38205 /$ imcr.020119

\section{Introduction}

Turmeric is a spice derived from the perennial herb Curcuma longa, which belongs to the ginger family Zingiberaceae, and was first cultivated in India over 4000 years ago. The orange-yellow powder of the dried rhizome is mentioned in the Charaka Samhita as having pleiotropic curative effects. In the past several decades, analytical methods have isolated several components of turmeric, termed curcuminoids, which include polyphenols such as curcumin $(1,2)$. A rising interest in turmeric outside of Ayurveda is exemplified by the published research in the past two decades. As of this writing, a Pubmed search for turmeric yielded over 5000 scientific abstracts, with the top three published countries being China, India, and USA, respectively. In India, turmeric mixed with warm milk is commonly used as a 'home remedy' for upper respiratory tract infections such as the common cold and sore throat (3). This brief report details the experience of using turmeric in this manner during a severe flu-like illness and some observations that suggest a potential role for turmeric in providing relief from the symptoms.

\section{Case presentation}

The patient was a 50-year old married male with children, and a research scientist by profession. His height and weight were $185 \mathrm{~cm}$ and $87 \mathrm{Kg}$ respectively. The BMI was 24.6 and within normal range, as calculated using the tool available online at https://www.nhlbi.nih.gov/health/educational/lose_wt/ $\mathrm{BMI} /$ bmicalc.htm (4). Approximately in the middle of March, first the children and then the parents, one of the latter who was the patient, developed a cold. The children also had high fever with chills at night. About a week later, all members of the family recovered. In the following week, the patient had a second bout of illness with an acute onset of the following symptoms: general weakness and lightheadedness, nightly chills, loss of appetite, mild nasal bleeding, low fever, diarrhea, and severe pain over paranasal sinuses under compression. The patient did not have a history of any chronic illnesses and was not taking any prescription medications.

During the period of illness which lasted one week, the patient independently switched to a diet summarized in the Table one below and as follows: approximately $400 \mathrm{~mL}$ of a cold beverage (chilled apple juice and water in roughly equal proportions $+15 \mathrm{~mL}$ of bottled lemon juice) the first thing in the morning. This was followed 2 hours later with approximately $240 \mathrm{~mL}$ of warm milk containing one teaspoonful of turmeric (unbranded turmeric powder obtained from a general store in India).

Approximately 10 minutes after the first drink of the turmeric milk, the patient noted an acute sense of warmth in the front of the face which lasted for 30 minutes and was accompanied by an almost complete relief of the sinus congestion and pain around the paranasal sinuses. Lunch and dinner predominantly consisted of approximately $400 \mathrm{ml}$ final volume of a beverage containing water with three tablespoons of curd made from whole cow's milk, $1 / 2$ cup of cooked sona masuri rice, and a small amount of salt, coarsely ground in a blender. This menu was strictly followed for five 5 days. 
Table 1: Summary of the diet followed (quantities given are approximate and at the level of precision of household use)

\begin{tabular}{|l|l|}
\hline Breakfast & $\begin{array}{l}1: 1(\mathrm{v} / \mathrm{v}) \text { chilled apple juice and water + } \\
15 \mathrm{~mL} \text { bottled lemon juice in a final volume } \\
\text { of } 400 \mathrm{~mL}\end{array}$ \\
\hline $\begin{array}{l}\text { Mid-morning } \\
\text { snack }\end{array}$ & $\begin{array}{l}240 \mathrm{~mL} \text { warm whole milk }+1 \text { tsp turmeric } \\
\text { powder }\end{array}$ \\
\hline Lunch & $\begin{array}{l}1 / 2 \text { cup of cooked rice }+3 \text { tbsp curd }(\text { dahi })+ \\
\text { water + salt in a final volume of } 400 \mathrm{~mL}\end{array}$ \\
\hline Dinner & Same as lunch \\
\hline
\end{tabular}

For another two days, this diet was supplemented with small amounts of solid food (approximately an additional half $1 / 2$ cup of cooked rice with dal or a vegetable curry). At the end of the sickness which lasted one week, some of the symptoms including the chills and fever faded away. Some symptoms persisted for a week after the illness. These included general weakness, breathlessness upon climbing stairs, occasional bouts of dizziness, and a loss of sense of smell to lavender (anosmia detected from the fragrance in shampoo used). The patient did not receive any supportive therapies to treat breathlessness. The remaining symptoms resolved on differing schedules over a period of approximately six 6 months (Figure 1).

The patient's weight reduced from $87 \mathrm{~kg}$ to $83 \mathrm{~kg}$ by the end of the first week. The pre-sickness weight was recovered in the following two weeks with the resumption of regular diet.

\section{Discussion}

Turmeric milk provided symptomatic relief from at least some of the symptoms described above. This statement is supported by the observation that approximately 10 minutes after the first drink of the turmeric milk, the patient experienced an acute relief from sinus congestion and pain accompanied by a sense of warmth in the front of the face. This response was repeated for the first four days of taking the drink and was not felt in later days as symptoms improved. Objective clinical measurements in similarly sick patients may help discover if there are acute physiological changes that correlate with any subjective patient reports upon turmeric consumption (e.g. changes in tissue perfusion). The scientific literature strongly supports a role for turmeric in alleviating flu-like symptoms: Turmeric and its constituents have been documented to have anti-inflammatory and anti-oxidant effects (1), which could prevent overactivation of the inflammatory cascade in response to a putative viral infection. Turmeric has also been suggested to have direct anti-viral activity in disrupting the viral envelope or blocking viral replication $(5,4)$. Any of these properties may be expected to provide broad protection from a viral infection. The widely used decongestant pseudoephedrine works by driving contraction of the microvasculature through adrenergic receptors $(6,5)$. It is tempting to speculate that the acute relief from congestion observed in this report may be the result of a direct effect of turmeric on the adrenergic receptors in the microvasculature $(7,6)$. It should be noted that some of the symptoms of the patient's illness are noted in many viral infections, including in mild cases of COVID-19, particularly the enduring loss of sense of smell, bleeding in the nose, dizziness, and the mild breathlessness which persisted after the sickness $(7,8)$. The patient was not tested for the presence of SARS-CoV-2 IgG in blood, which would be diagnostic of exposure $(9,8)$.

Although previous small-scale studies using materials described in Ayurveda and other systems of medicine have been shown to ameliorate disease $(10,11)$, the knowledge has not translated to the clinical use of these materials in modern medicine due to the need for controlled clinical trials. Additionally, developing mouse models to understand the longterm health effects of turmeric (12), identifying and testing biomarkers $(13,14)$, and genetic screening, will help more comprehensively understand the effects of turmeric on the human body (15).

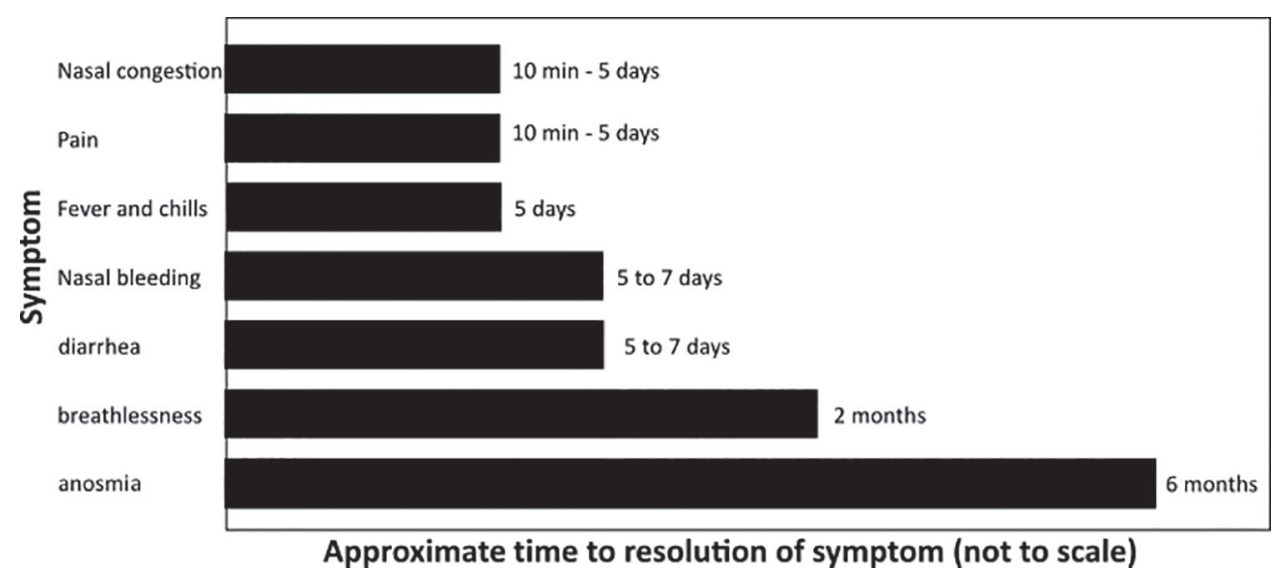

Fig. 1: Approximate time course of resolution of symptoms described. 


\section{Limitations}

The above symptoms and the experience have been reconstructed approximately 10 weeks after the illness and are subject to the limitations of human memory.

\section{Conclusions}

A report of the experience of a flu-like illness in early March of 2020 with upper respiratory tract involvement is presented. While the report is anecdotal and necessarily subjective, there are several aspects of interest with respect to the potential role of turmeric in providing relief, as discussed above. Regardless of the mechanism, there are currently no clinically approved indications for the use turmeric or its constituents as a treatment for any medical condition, including relief from upper respiratory tract infections, while there is a wealth of anecdotal evidence and supporting pre-clinical data (1). Since turmeric has minimal to no safety concerns, it is of great benefit to conduct a well-designed clinical trial to test if turmeric as a dietary supplement provides a clinical benefit to patients suffering from cold and influenza-like symptoms.

\section{Acknowledgements}

The author wishes to acknowledge the suggestion from Dr. Akshay Anand to write this report, and the critical reading of the manuscript by Madhava Sai Sivapuram.

\section{Authorship contributions}

K.B. designed the regimen and wrote the manuscript.

\section{Informed consent}

Yes.

\section{Source of funding}

None applicable.

\section{Conflict of interest}

The author reports no conflict of interest.

Received Date: 26-05-20; Revised Date: 07-10-20

Accepted Date: 01-12-20

\section{References}

1. Chattopadhay I, Biswas K, Bandyopadhay U, Banerjee RK. Turmeric and curcumin: Biological actions and medicinal applications. Current Science. 2004;87(1):44-53.

2. Srinivasan KR. A chromatographic study of the curcuminoids in Curcuma longa, L. J Pharm Pharmacol. 1953;5(7):448-57.

3. Vats V. Turmeric Benefits: Make Turmeric Your Best Friend This Winter; Know Health Benefits And Ways To Use It [Internet]. NDTV.com. NDTV; 2019 [cited 2020Nov21]. Available from: https://www.ndtv. $\mathrm{com} /$ health/turmeric-benefits-make-turmeric-your-best-friendthis-winter-know-health-benefits-and-ways-to-use-it-2147672

4. Calculate Your BMI - Standard BMI Calculator [Internet]. National Heart Lung and Blood Institute. U.S. Department of Health and Human Services; [cited 2020Nov21]. Available from: https://www.nhlbi.nih. gov/health/educational/lose_wt/BMI/bmicalc.htm

5. Praditya D, Kirchhoff L, Bruning J, Rachmawati H, Steinmann J, Steinmann E. Anti-infective Properties of the Golden Spice Curcumin. Front Microbiol. 2019;10:912.

6. Drew CD, Knight GT, Hughes DT, Bush M. Comparison of the effects of D- $(-)$ ephedrine and L-(+)-pseudoephedrine on the cardiovascular and respiratory systems in man. Br J Clin Pharmacol. 1978;6(3):221-5.

7. Dewar AM, Clark RA, Singer AJ, Frame MD. Curcumin mediates both dilation and constriction of peripheral arterioles via adrenergic receptors. J Invest Dermatol. 2011;131(8):1754-60.

8. Singhal T. A Review of Coronavirus Disease-2019 (COVID-19). Indian J Pediatr. 2020;87(4):281-6.

9. Hoffman T, Nissen K, Krambrich J, Ronnberg B, Akaberi D, Esmaeilzadeh M, et al. Evaluation of a COVID-19 IgM and IgG rapid test; an efficient tool for assessment of past exposure to SARS-CoV-2. Infect Ecol Epidemiol. 2020;10(1):1754538.

10. Kumar S, Modgil S, Bammidi S, Minhas G, Shri R, Kaushik S, et al. Allium cepa exerts neuroprotective effect on retinal ganglion cells of pterygopalatine artery (PPA) ligated mice. Journal of Ayurveda and Integrative Medicine. 2020.

11. Mathur D, Goyal K, Koul V, Anand A. The molecular links of re-emerging therapy: a review of evidence of Brahmi (Bacopa monniera). Frontiers in pharmacology. 2016;7:44.

12. Anand A, Banik A, Thakur K, L Masters C. The animal models of dementia and Alzheimer's disease for pre-clinical testing and clinical translation. Current Alzheimer Research. 2012;9(9):1010-29.

13. Anand A, Gupta PK, Sharma NK, Prabhakar S. Soluble VEGFR1 (sVEGFR1) as a novel marker of amyotrophic lateral sclerosis (ALS) in the North Indian ALS patients. European Journal of Neurology. 2012;19(5):788-92.

14. Sharma NK, Prabhakar S, Gupta A, Singh R, Gupta PK, Gupta PK, et al. New biomarker for neovascular age-related macular degeneration: eotaxin-2. DNA and cell biology. 2012;31(11):1618-27.

15. Vinish M, Prabhakar S, Khullar M, Verma I, Anand A. Genetic screening reveals high frequency of PARK2 mutations and reduced Parkin expression conferring risk for Parkinsonism in North West India. Journal of Neurology, Neurosurgery \& Psychiatry. 2010;81(2):166-70. 